\title{
LA PERSPECTIVA DOCENTE ACERCA DE LA NOCIÓN DE FAMILIA DE NIÑOS Y NIÑAS PREESCOLARES COSTARRICENSES Y EXTRANJEROS CENTROAMERICANOS
}

\author{
Arce Villalobos, Doris Rocío ${ }^{2}$, Carballo León, Alejandra ${ }^{3}$, \\ Castro Castro, Karla Alejandra ${ }^{4}$, Pereira Pérez, Zulay ${ }^{5}$
}

\section{Resumen}

El presente artículo retoma algunos de los resultados y conclusiones de una investigación realizada en instituciones preescolares costarricense acerca de la noción de familia, tanto de niños y niñas costarricenses como extranjeros centroamericanos. Importante de resaltar es que los infantes tienen una noción de familia muy ligada a las experiencias y vivencias de su propia realidad. Se logra determinar una diferencia puesto que, según los docentes, para los costarricenses la familia es nuclear, en tanto que para los extranjeros es más extensa por cuanto reconocen como parte de la familia a personas que no conviven con ellos.

\section{Abstract}

Article based on the results and conclusions drawn in a research about the concept of family held by Costa Rican and foreign Central American preschoolers. The concept these children have is closely related to the real-life experiences they have lived. It was possible to establish a difference since - according to the teachers- Costa Ricans view the family as nuclear while foreign children view it as extensive since they consider that relatives living outside the household are also part of the family.

Descriptores: noción de familia, educación preescolar, niños y niñas nacionales y extranjeros centroamericanos.

\footnotetext{
${ }^{1}$ Solamente con propósitos de sencillez, en este artículo se utiliza un formato tradicional que no contempla las diferencias de género. Sin embargo, las autoras no comparten ninguna discriminación en este sentido.

2 Licenciada en Educación Preescolar. Docente de preescolar.

${ }^{3}$ Licenciada en Educación Preescolar. Docente de I Ciclo de Educación General Básica.

${ }^{4}$ Licenciada en Educación Preescolar. Bachiller en Psicología

5 Catedrática de la Universidad Nacional. Máster en Psicología de la Universidad de Costa Rica. Excoordinadora e Investigadora del Programa de Investigación en Epistemología Genética y Educación del IMEC, Universidad de Costa Rica. Exdirectora de la División de Educación Básica del CIDE-UNA. Actualmente se desempeña como docente e investigadora en el Centro de Investigación y Docencia en Educación. Tiene publicaciones en el campo de la Psicología.
} 

omando en cuenta que las políticas educativas deben procurar construir ambientes educativos que contemplen la multiculturalidad desde una perspectiva positiva, se realizó una investigación acerca de la noción de familia de niños costarricenses y extranjeros centroamericanos que asisten a un jardín público. Este es en un aporte para que el conocimiento de los factores relacionados con la diversidad cultural existente dentro de las aulas, no se considere como un obstáculo en los procesos de construcción de conocimientos, sino como una dimensión valiosa que puede enriquecerlos.

Desde esa perspectiva de diversidad, cabe plantearse el conocer las diferentes nociones o conceptos que tienen los estudiantes que asisten a las instituciones educativas del país. En el caso particular de la investigación que originó este artículo, fue la noción de familia la que se indagó desde la visión de niños y niñas costarricenses y extranjeros centroamericanos, misma que se complementó con la opinión de docentes en servicio en el nivel preescolar.

En este sentido, acercarse a comprender las nociones de familia de los niños y las niñas costarricenses y extranjeros centroamericanos, es parte del reto que cada educador debe asumir, si está dispuesto a apropiarse de una actitud de compromiso en la promoción de procesos educativos contextualizados, que tengan como eje las diferencias individuales y culturales de los estudiantes.

Al hacer una revisión de estudios realizados en el ámbito costarricense, acerca de nociones o conceptos, independientemente si se refieren o no a la noción de familia, es posible encontrar los trabajos de Polanco y Ramírez (1990), Marino (1995), Delgado y Espinoza (1997), Villalobos (1998), Alvarado y Rodríguez (2000), Mora (2001), Bolaños y Castro (2001) Carballo y Vargas (2002), León, Pereira y Castro, (2003), y más recientemente un trabajo sobre concepto de familia de Arce, Carballo, Castro y Pereira, 2004, entre otros.

A nivel internacional, pueden citarse trabajos como los de Fuentes y Ruiz (1988), Gutiérrez (1999), Muriá (2000), Maldjian y Noguera (2000), Contreras, Morelli, Uccelli y Peusner (2002) y otros.

En general, estos trabajos abarcan el tema de construcción de conceptos en niños y niñas; en su mayoría, profundizan en el desarrollo cognitivo, según sean con los procesos constructivos de los distintos conceptos. No obstante, se nota la carencia de investigaciones que permitan conocer las nociones o conceptos que poseen niños y niñas de diferentes culturas que interactúan en un mismo contexto.

Al analizar las conclusiones de esos estudios, es posible señalar la relación entre el nivel conceptual del niño y su nivel evolutivo. A medida que evolucionan cognitivamente, también evolucionan en nivel conceptual, sin obviar el hecho de que las experiencias con el entorno promueven la movilización 
cognitiva de los sujetos participantes en los estudios.

Como parte de las demandas que recaen sobre el Estado costarricense, a partir de los diferentes procesos migratorios a que está sometido el país, existe necesidad de que las instituciones educativas asuman parte de esas demandas, ya que son un ente activo en la configuración de cambios sociales; por lo tanto, puede señalarse que hay afinidad entre la labor de la escuela y la familia, pues ambos entes buscan el desarrollo integral del niño. Para lograrlo, han de considerar la individualidad y desde el plano social las características heterogéneas que muestra la población costarricense.

Esta heterogeneidad crea en las aulas costarricenses una situación especial y enriquecedora; la multiculturalidad se constituye así en una característica de la población que asiste a las escuelas de Costa Rica. Dentro de este ámbito, el trabajo docente debe enfocar, entre otras dimensiones: las características socioculturales de cada uno de sus estudiantes; el tema de la familia y las relaciones intrafamiliares constituye un ámbito de nuevas realidades y demandas que han de ser asumidas por los procesos educativos de carácter formal.

Por ello, es pertinente analizar la noción de familia de infantes costarricenses y extranjeros centroamericanos, y abordar tangencialmente los procesos migratorios que se han dado en Costa Rica. Según Ebanks (1993), la migración
Comprender las nociones que sobre la familia tienen los abordar las diversas acepciones que, entorno a dicho concepto, tienen sus estudiantes y el manejo en el aula, comprendiendo que existe una serie de factores culturales que se evidencian en la realidad familiar y escolar

\section{Acercarse a comprender las} nociones de familia de los niños y las niñas costarricenses y extranjeros centroamericanos, es parte del reto que cada educador debe asumir, si está dispuesto a apropiarse de una actitud de compromiso en la promoción de procesos educativos contextualizados, que tengan como eje las diferencias individuales y culturales de los estudiantes. estudiantes, le permite al docente sociales, políticos, económicos y 
se define como “(...) un traslado o cambio de residencia que supone abandonar una zona política administrativa e ingresar en otra durante un período prolongado de tiempo" (p. 38).

Algunas de las situaciones políticas y socioeconómicas imperantes en los países centroamericanos, han convertido a Costa Rica, desde hace varios años, en el principal país receptor de inmigrantes. En su mayoría, estos son de origen nicaragüense, salvadoreño, aunque existen otros inmigrantes de habla hispana. Con respecto al primer grupo, las estadísticas brindadas por la Facultad Latinoamericana de Ciencias Sociales (FLACSO, 1999), señalan que el $91 \%$ del universo que se acogió al régimen de amnistía son inmigrantes originarios de Nicaragua.

Comprender las nociones que sobre la familia tienen los estudiantes, le permite al docente abordar las diversas acepciones que, en torno a dicho concepto, tienen sus estudiantes y el manejo en el aula, comprendiendo que existe una serie de factores sociales, políticos, económicos y culturales que se evidencian en la realidad familiar y escolar. Estos factores se convierten en parte de la práctica del profesional en educación. Para el docente, es importante considerar la comprensión de la noción de familia que tienen sus estudiantes para así propiciar los espacios de interacción entre ambas instituciones educativas: familia y escuela.

Con la creciente incorporación de los niños preescolares extranjeros centroamericanos a las aulas del sistema educativo costarricense, la investigación realizada se ha constituido en un valioso aporte teórico al docente que se enfrenta, cotidianamente, al trabajo con esta población y al reto de integrarla dentro del aula.

Nuestro interés es que el maestro cuente con un referente teórico que le permita comprender las características, intereses, necesidades y diferencias individuales de sus estudiantes a partir del ámbito de la familia, para que partiendo de ellas pueda generar estrategias de integración en los procesos educativos. Además, conociendo estas diferencias y semejanzas, el docente tendrá las herramientas conceptuales para adecuar el currículo a la diversidad sociocultural y contextualizar las experiencias pedagógicas; así se responde a la realidad de cada uno de sus estudiantes.

En este mismo sentido, el estudio realizado por Arce et al. (2004), se constituye en un importante referente teórico para propiciar la incorporación de la multiculturalidad en los procesos pedagógicos ý que no quede plasmada sólo como un eje transversal en la elaboración del currículo de preescolar, sino que sea vivida en el proceso educativo.

Es pertinente señalar que la diversidad, como fenómeno universal, incrementa la existencia de sociedades étnicamente pluralistas, dado que la cultura, 
al igual que la educación, se encuentra permeada por elementos presentes en la sociedad.

Arnaiz (1999) afirma que el hecho multicultural es una realidad en nuestra sociedad, debido a los movimientos migratorios de humerosos grupos sociales de características culturales específicas, que determina que diversas culturas compartan el mismo territorio, la misma sociedad y los mismos centros educativos. El término diversidad nace precisamente, para acabar con cualquier tipo de discriminación, generar oportunidades para todos y abrir un amplio abanico con respecto al ser diferente.

En esta misma tendencia, Vilas (2001) recalca que el término diversidad

(...) es el resultado de la combinación de las culturas nacionales, comarcales o locales, las de las minorías étnicas, las de las diferentes clases o estratos sociales,... además de la concurrencia multicultural en un ámbito territorial determinado, la creciente influencia de los medios audiovisuales y de comunicación, cuestiona el concepto tradicional de entomo, al superarse muchos de los condicionantes derivados de la cercanía física (p. 1).

Asimismo, el autor considera que la diversidad cultural puede tener múltiples manifestaciones: puede y debe favorecer el enriquecimiento cultural, el desarrollo de valores y la profundización de la democracia. No obstante, también aparecen problemas derivados de ésta, como: el desarraigo, la barrera idiomática, la situación administrativa-legal, la carencia de políticas educativas integradoras y los insuficientes planteamientos de Educación Multicultural e Intercultural por parte de los agentes educativos. Recalca también, que son estos aspectos negativos los que generan los choques culturales derivados del desconocimiento mutuo, la exclusión social, la xenofobia, el racismo, entre otras manifestaciones.

Asimismo, señala que “(...) la aceptación de la convivencia en diversidad exige y demuestra la aceptación de una dinámica sumamente compleja de las relaciones humanas y de la comunicación asertiva" (p. 2). Por lo tanto, según el autor, la capacidad de valorar la diversidad permite desarrollar óptimamente las relaciones humanas.

La escuela constituye un espacio que cuenta con población cultural y étnicamente pluralista, por lo que dicho autor argumenta que "(...) la diversidad existe en todos los centros educativos del mundo, representada por varios aspectos en los que los seres humanos solemos diferir" (p. 10). Considera que no se puede negar la importancia de conocer la diversidad cultural, valorando 
las peculiaridades de las personas, la diversidad social y la personal e individual, la cual se ve reflejada en el aula y se remite a cada niño en particular.

Según su criterio, muchos autores coinciden en que los centros educativos son el centro donde confluyen y se representan los diferentes caracteres de la heterogeneidad personal y cultural de las comunidades a las que pertenecen. Por lo tanto, se convierten en lugares perfectos para aprovechar la riqueza de esa diversidad y lograr un desarrollo en el que todas las identidades sean valoradas, y se promueva una vida en democracia, la cooperación y el respeto mutuo. Las instituciones escolares son el espacio justo para construir la paz y la equidad, enseñando a los estudiantes a responder ante la injusticia y la desigualdad.

Por todo lo anterior, se reconoce la importancia de tomar en cuenta la diversidad dentro del currículo. Amaiz y Marchesi (1999) exponen que

(...) un currículo abierto a la diversidad de los alumnos es un currículo que se plantea a todos los alumnos para que todos aprendan quiénes son los otros, y qué debe incluir; en su conjunto y en cada uno de sus elementos, la sensibilidad hacia las diferencias que hay en la escuela (citado por Arnaiz, 1999, p. 12) y en la sociedad en general.

La escuela debe brindar una educación para todos, de calidad e igualdad, en la que la realidad del niño no se encuentre fuera del aula. Con esto, poder asumir las trasformaciones étnicas de manera que se disfrute y aprenda de otras culturas.

En resumen, lo señalado insta a la búsqueda de un currículo común, diversificado y en esencia que permita la expresión de las diferencias y no la desigualdad. Puede concluirse entonces, que "la escolarización no es todopoderosa para combatir las desigualdades, pero lo que no debe hacer nunca es ser ella causa de mayor desigualdad, dando trato diverso o reforzando la jerarquía entre sujetos diferentes" (Gimeno, 2001, p. 61).

Cabe señalar que Costa Rica se ha caracterizado por ser un país receptor de población migrante, debido a que las condiciones socioeconómicas con las que cuenta son evidentemente favorables, frente a las condiciones que presentan otros países En este sentido, Brenes (1999) indica que la migración de nicaragüenses, panameños y estadounidenses han sido las más constantes durante este siglo; mientras que la de salvadoreños y cubanos se han intensificado a partir de los años ochenta.

Agrega que, la población inmigrante más importante en número ha sido la nicaragüense, como resultado de la situación interna que vive su país. Explica la 
Comisión para la Defensa de los Derechos Humanos en Centroamérica (citado por Arce, 2003), que han sido cuatro los momentos principales en que se han intensificado las migraciones de población nicaragüense.

Dado que no sólo se dan cambios en la composición étnica de la población, sino que también en el ámbito de instituciones educativas se van percibiendo variaciones que han de ser considerados por el docente. Resulta necesario, entonces, valorar las implicaciones que la multiculturalidad demanda a la escuela como institución social.

Asumir las condiciones e implicaciones de la diversidad como una realidad educativa, implica la consolidación de una escuela intercultural; es decir, atender las necesidades de la población nacional e inmigrante. Azofeifa, Céspedes, Monge y Vidal (2001) explican que

La educación intercultural es un proceso mediante el cual se establece un marco que facilita la interacción cultural en un plano de igualdad entre todos los seres humanos. Es un espacio permanente donde las personas tienen las oportunidades de interactuar, aceptando y respetando las diferencias culturales y donde se reconoce que esas diferencias de "los otros", son esenciales para desarrollar nuevas cosmovisiones con perspectiva étnicamente amplias, heterogéneas, que favorecen la aprehensión de realidades distintas (p. 137).

En este sentido, es necesario reconocer la importancia que tiene una pedagogía intercultural dentro de la educación, ya que ésta contribuye a la interrelación y convivencia de diferentes grupos culturales que convergen en los procesos educativos. Para Azofeifa et al. (2001), la pedagogía intercultural beneficia a las comunidades escolares con espacios educativos que atienden las particularidades étnicas de los grupos, con el fin de favorecer la construcción de una sociedad intercultural.

Según los autores, la educación intercultural debe partir del análisis de hechos universales que caracterizan a los individuos y desde ahí, hacia el tratamiento de la diversidad cultural en el aula. Para ello, se considera necesario promover procesos educativos que fortalezcan la interacción cultural valorando la diversidad.

En el desarrollo humano y especialmente en la comprensión de éste en los primeros años de vida, se reconoce la suprema importancia de la familia, como la primera institución social en la que está inmerso el niño. Señala Arias (2001) que 
El niño es el único ser vivo que nace y sin la ayuda del adulto, durante un prolongado periodo de tiempo, no logra un desarrollo de su existencia, pero paradójicamente a esta aparente insuficiencia adaptativa, posee la capacidad para la educabilidad, para que mediante la ayuda y colaboración con los otros se convierta en una persona independiente, autónoma, que contribuya a la educabilidad de los demás y con su creatividad y trabajo al enriquecimiento de la cultura humana (p. 1).

Esos "otros" señalados anteriormente, remiten a la función social de la familia, como la institución en la que el niño participa de las primeras interacciones con las personas significativas que le rodean, posibilitando su participación activa en las experiencias cotidianas que en última instancia inciden en su desarrollo integral. Sin embargo, aunque parece existir un consenso histórico sobre su importancia e impacto en el desarrollo individual y social, si se busca establecer una concepción y caracterización sobre la familia, se encuentran diversas corrientes de pensamiento, que en algunos casos son contradictorias.

$\mathrm{Al}$ respecto, menciona Linton (citado por Campos y Smith, 1999) que al poseer cada sociedad sus creencias, valores y pautas de acción, las instituciones que se derivan de su combinación, serán diferentes en su forma y contenido. Pese a ello, todos los sistemas sociales contienen instituciones que corresponden a lo que se llama familia. Por lo que el grupo familiar se ha considerado como intermedio entre el individuo y la sociedad a la que pertenece y posee también, funciones y reglas definidas de interacción interna (define cómo se relacionarán entre sí los individuos que la componen) y de interacción externa (pautas de relación con otras familias, comunidad y sociedad).

Partiendo de una visión integral de la educación, que toma en cuenta tanto los procesos educativos informales como aquellos de carácter formal, la función de la familia en este sentido, es central y trascendental tomando en cuenta que desde que el niño nace e incluso antes de este momento su desarrollo está mediatizado por lo cultural y lo social que confluye en su ambiente familiar. Es así como "el contexto sociocultural que se crea, en el entomo familiar; desde el mismo momento de la concepción de un niño, se constituye en una condición psicológica del ser humano" (Arias, 2001, p. 3).

Pero además, afirma Criado (1994) que

La familia no es sólo el medio afectivo y tranquilizador para el desarrollo psíquico del niño, es además un medio sociocultural en el que se 
producen una serie de acciones y reacciones. El niño en contacto con la familia descubre al otro, al grupo, la coacción, las prohibiciones, las limitaciones de su expresividad, la rivalidad, la solidaridad, a la vez que el sistema de valores de la clase social a la que pertenece (p. 31).

Bajo esta perspectiva, los padres de familia y demás figuras de autoridad actúan como agentes socializadores, que propician una dinámica y una organización familiar según las condiciones sociales y culturales en los que está inmersa la familia como tal. Por esta razón Ackerman (citado por Carvajal y Guang, 2003, p. 16) considera que “(...) la familia es extraordinariamente sensible a las necesidades de las personas que la componen y a su medio comunitario más amplio".

El estudio que sirve de base para la presentación de este artículo, fue de carácter exploratorio. El mismo se realizó en dos instituciones públicas de la Provincia de San José del circuito 01, catalogadas como escuelas de atención prioritaria. Las participantes fueron diez docentes de educación preescolar, las cuales fueron escogidas por estar a cargo de los niños participantes en el estudio o por trabajar en esos centros educativos. Todas ellas docentes en propiedad, con grados académicos de Licenciatura (nueve) y Maestría (una).

Por otra parte, los niños y las niñas fueron inicialmente identificados como costarricenses (hijos de padres costarricenses) o como extranjeros centroamericanos (hijos de padres centroamericanos y nacidos en algún país centroamericano). Cabe mencionar que una vez realizada la selección, la totalidad de los niños y niñas fue de nacionalidad nicaragüense. Para efectos del presente artículo, se retomarán únicamente los datos aportados por las docentes participantes.

\section{Resultados}

El análisis de datos se presenta mediante matrices, lo que permitió identificar su criterio con respecto a la noción de familia que poseen los niños costarricenses y extranjeros centroamericanos a su cargo (ver matriz 1).

Las docentes de preescolar expresan varios criterios en cuanto a la importancia de conocer la noción de familia que poseen los niños a su cargo. Dos de las docentes consideran que indagar acerca de este concepto desde la perspectiva de los niños, resulta importante para obtener información sobre la realidad familiar que estos viven, que en algunos casos es difícil de obtener y que influye directamente en su proceso educativo. Por esta razón, algunas docentes consideran que dicho concepto debe ser el primer contenido temático que se debe desarrollar en el curso lectivo. 
Matriz 1

Valoración de las docentes acerca de la oportunidad de conocer la noción de familia que poseen los niños a su cargo

\begin{tabular}{|c|c|}
\hline Informantes & Respuesta \\
\hline Docente 1 & $\begin{array}{l}\text { "Es muy importante, ya que de ella, uno como maestro puede des- } \\
\text { prender información que muchas veces los padres por vergüenza o } \\
\text { por conveniencia no se atreven a dar. Es el tema con el cual se debe } \\
\text { empezar". }\end{array}$ \\
\hline Docente 2 & $\begin{array}{l}\text { "Que casi todos o en su mayoría, todos conocen de forma sencilla } \\
\text { qué es una familia". }\end{array}$ \\
\hline Docente 3 & $\begin{array}{l}\text { "Es muy baja, ya que las familias de aquí la mayoría son sin imagen } \\
\text { paterna". }\end{array}$ \\
\hline Docente 4 & $\begin{array}{l}\text { "Considero que es importante porque esto refleja el modo en que } \\
\text { ellos viven, la realidad de sus vidas y esto influye en su aprendizaje". }\end{array}$ \\
\hline Docente 5 & $\begin{array}{l}\text { "Los niños a mi cargo consideran que la familia son todas las perso- } \\
\text { nas que viven con ellos y los cuidan". }\end{array}$ \\
\hline Docente 6 & $\begin{array}{l}\text { "Es necesario trabajar este tema, pues muchos de los niños y niñas } \\
\text { no logran identificar concretamente a su familia". }\end{array}$ \\
\hline Docente 7 & $\begin{array}{l}\text { "Es importante, ya que a partir de esa noción que traen los niños, se } \\
\text { empieza a trabajar. Y de todas formas, el concepto tradicional de fa- } \\
\text { milia no lo tienen; la mayoría proviene de dos hogares constituidos } \\
\text { por abuelos, mamá e hijos". }\end{array}$ \\
\hline Docente 8 & $\begin{array}{l}\text { "Es importante conocer la noción de familia que tienen los niños, ya } \\
\text { que algunos de ellos viven con tíos y abuelos. También unos niños } \\
\text { viven solamente con su madre y no con su padre". }\end{array}$ \\
\hline Docente 9 & $\begin{array}{l}\text { "Es sumamente importante para lograr partir de sus experiencias, } \\
\text { intereses y necesidades para construir su aprendizaje". }\end{array}$ \\
\hline Docente 10 & $\begin{array}{l}\text { "Es muy importante yo encue!n"ว los puntos débiles que tengo que } \\
\text { reforzar para que el niño gane . guridad y que esté ubicado en el } \\
\text { concepto correcto de familia que practicamos". }\end{array}$ \\
\hline
\end{tabular}


En relación con lo anterior, una de las docentes manifiesta que al profundizar en la noción de familia de los niños, se estará partiendo de sus experiencias, intereses y necesidades en el proceso de construcción de sus conocimientos. Otro aspecto que se rescata de las respuestas obtenidas, se relaciona con el concepto tradicional de familia y la transformación que ésta ha sufrido en la actualidad.

Al respecto, el criterio de tres de las docentes está relacionado con el hecho de que al conocer dicha noción en los niños, se devela la estructura familiar en la que ellos están inmersos. Expresan que esta noción ya no es la tradicional (padres e hijos), sino que responde a la de familias constituidas por otros miembros como abuelos, tíos u hogares monoparentales.

De tal manera, para algunas de ellas, desarrollar esta temática podría acercarlas a una mayor comprensión del contexto familiar y de las personas significativas que participan e intervienen en el desarrollo de los niños. Resulta interesante, además, la respuesta de una docente quien expresa la posibilidad de reforzar aspectos como la seguridad del niño al conocer la noción que éste ha construido, pero en especial ella opina que se puede ayudar a que los niños estén ubicados en "el concepto correcto de familia que practicamos". Esta afirmación de un concepto "correcto" de familia podría explicarse por factores socioculturales en la sociedad costarricense, por los cuales el modelo "ideal" de familia es aquel en el que un conjunto de personas (usualmente mamá, papá e hijos) unidos por lazos consanguíneos conviven en un mismo hogar. Es importante señalar también que una de las respuestas no es aplicable a la pregunta asignada, pues la docente contestó por los niños y no por ella (ver matriz 2).

Ante el cuestionamiento sobre cómo elaboran los niños preescolares la noción de familia, nueve de las docentes participantes coinciden en el papel del contexto social, comunal, en el que el niño crece y, específicamente, el ambiente familiar en el que se desarrolla, son los medios que propician las vivencias, experiencias e interacción con las personas significativas y, por ende, el proceso de construcción de la noción de familia en los niños.

Ahora bien, los criterios de las docentes se orientan especialmente al factor sociocultural y al proceso de internalización propuesto por Vigotsky (citado por Hernández, 1998) en el cual las vivencias externas, las relaciones con las personas que les rodean diariamente, la observación y vivencia de roles, entre otros aspectos señalados, forman parte de la dimensión interpsicológica. Es así como a medida que el niño va evolucionando en su desarrollo cognitivo, los aspectos señalados formarán parte de su construcción intrapsicológica, en este caso de lo que es su noción y posteriormente su concepto de familia.

El proceso de índole sociocultural y a su vez intrafamiliar que identifican las docentes, permite señalar que la noción que los niños a su cargo elaboran, 
Matriz 2

Consideraciones del docente acerca de cómo elaboran los niños preescolares a su cargo la noción de familia

\begin{tabular}{|c|c|}
\hline Informantes & Respuesta \\
\hline Docente 1 & $\begin{array}{l}\text { "Creo que es una noción que ellos van construyendo desde el mo- } \\
\text { mento en que empiezan a relacionarse con sus diferentes miembros. } \\
\text { Es una noción "abierta" que se va enriqueciendo". }\end{array}$ \\
\hline Docente 2 & $\begin{array}{l}\text { "Mediante el dibujo ellos representan a su familia dibujando a mamá, } \\
\text { papá y ellos". }\end{array}$ \\
\hline Docente 3 & "Por medio de las experiencias personales". \\
\hline Docente 4 & $\begin{array}{l}\text { "Con la convivencia de sus familias y de lo que observan a su } \\
\text { alrededor". }\end{array}$ \\
\hline Docente 5 & $\begin{array}{l}\text { "Ellos lo elaboran por el medio en que viven, por las situaciones que } \\
\text { cambian diariamente". }\end{array}$ \\
\hline Docente 6 & $\begin{array}{l}\text { "Con las vivencias que tienen y las enseñanzas que reciben de la } \\
\text { institución". }\end{array}$ \\
\hline Docente 7 & "A partir de su experiencia". \\
\hline Docente 8 & $\begin{array}{l}\text { "Los niños elaboran la noción de familia, tomando en cuenta ¿cómo } \\
\text { está conformado su hogar? en la realidad". }\end{array}$ \\
\hline Docente 9 & $\begin{array}{l}\text { "Paulatinamente con la interacción con la gente con la cual habita, } \\
\text { observando los roles de todos; y en la clase notando similitudes y } \\
\text { diferencias con las familias de sus pares". }\end{array}$ \\
\hline Docente 10 & $\begin{array}{l}\text { "Ellos identifican a su familia a las personas que viven a diario con } \\
\text { ellos". }\end{array}$ \\
\hline
\end{tabular}

parte de lo que Hernández (1998) llama elaboración de conceptos espontáneos, ya que se construyen como consecuencia de las experiencias cotidianas de los niños. Ahora bien, estas nociones espontáneas, se someten a la interpretación y 
reconstitución de cada pequeño. En este proceso, dos de las docentes mencionan un aspecto fundamental, al expresar que los niños elaboran la noción de familia con ayuda de los conocimientos que construyen en la institución educativa y mediante vivencias y observación de las otras familias de sus pares.

Son precisamente la escuela y los pares, los que además de las personas que conviven diariamente con los niños y las niñas, juegan un papel fundamental en la transición de los conocimientos espontáneos a lo que Hernández (1998) define como conocimientos científicos, más complejos y abstractos. Podría decirse que es mediante las experiencias concretas, diarias con su familia y en el proceso educativo formal que el niño va construyendo su propia noción de familia que no es rígida, sino más bien una noción compleja hasta convertirse en un concepto "científico" propio de la reflexión y de la internalización del saber (ver matriz 3).

Las respuestas de las docentes en cuanto a la noción de familia que tienen los niños costarricenses a su cargo, señalan varios elementos importantes. Según el criterio de cinco de las docentes, los niños costarricenses han elaborado una noción de familia tradicional, correspondiente a una estructura familiar compuesta por papá, mamá e hijos o familia nuclear. Sin embargo, una de estas docentes menciona que los niños reconocen que en muchas de las familias un miembro, en su mayoría el padre, está ausente.

Por otra parte, dos de las docentes expresan que los niños reconocen como familia a las personas que viven con ellos, en una misma casa. Por lo tanto, según cada caso particular, la noción de familia responde a una estructura que integra a padres, hijos, abuelos, tíos, amigos y vecinos. Otra docente señala que - los niños costarricenses identifican a su familia claramente gracias a que estos poseen una mayor estabilidad como grupo familiar.

Como lo señala Ackerman (citado por Carvajal y Guang, 2003), las respuestas de las docentes podrían señalar que la noción de familia construida por los niños está impregnada por la heterogeneidad y convivencia de diversas estructuras familiares (familia monoparental, nuclear, extensa, compleja). En este sentido, no se puede hablar de un único patrón familiar inscrito en dichas nociones, sino de diversos modelos familiares emergentes. Sin embargo, es importante agregar que, según las respuestas, prevalece el modelo tradicional de familia nuclear, que históricamente ha dominado a esta institución social, bajo patrones patriarcales fuertemente arraigados en la sociedad costarricense.

En la matriz 4, resulta interesante señalar que, en cuanto a la noción de familia que tienen los niños extranjeros centroamericanos, cuatro de las docentes mencionan que en este caso, los niños a su cargo identifican a sus familias dentro de una estructura de familia extensa, porque además de sus padres, 
Matriz 3

Consideraciones del docente acerca de la noción de familia que tienen niños y niñas costarricenses a su cargo

\begin{tabular}{|c|c|}
\hline Informantes & Respuesta \\
\hline Docente 1 & $\begin{array}{l}\text { "Cuando estudiamos el tema, ellos decían que la familia eran perso- } \\
\text { nas que vivían en una casa. Luego conforme avanzamos agregaron } \\
\text { que estaba formada por hermanos, la mamá, el papá y otros parientes } \\
\text { según cada caso particular. A veces agregan amigos y vecinos". }\end{array}$ \\
\hline Docente 2 & $\begin{array}{l}\text { "La de tomar en cuenta a "papá", "mamá" e hijos como su familia } \\
\text { inmediata". }\end{array}$ \\
\hline Docente 3 & $\begin{array}{l}\text { "El nivel de educación no tiene tanto que ver con la nacionalidad, } \\
\text { sino con el lugar donde ellos viven". }\end{array}$ \\
\hline Docente 4 & $\begin{array}{l}\text { "La mayoría piensa que familia es el papá, la mamá y los niños, pero } \\
\text { reconocen que muchas familias no tienen a uno de los padres en la } \\
\text { mayoría el papá". }\end{array}$ \\
\hline Docente 5 & $\begin{array}{l}\text { "Para los costarricenses su familia está aquí en el país obvio y los } \\
\text { niños nicaragüenses añoran su país". }\end{array}$ \\
\hline Docente 6 & $\begin{array}{l}\text { "La noción que tienen es que ellos y sus padres, tíos, abuelos o quie- } \\
\text { nes viven en ellas son su familia". }\end{array}$ \\
\hline Docente 7 & "Del núcleo constituido por mamá, papá e hijos". \\
\hline Docente 8 & $\begin{array}{l}\text { "Los niños costarricenses tienen la noción de que la familia está inte- } \\
\text { grada por la mamá, papá y hermanos". }\end{array}$ \\
\hline Docente 9 & $\begin{array}{l}\text { "Notan como familia a sus padres y hermanos y conviven en una } \\
\text { misma casa". }\end{array}$ \\
\hline Docente 10 & $\begin{array}{l}\text { "Identifican claramente a la familia porque tienen mayor estabilidad } \\
\text { como grupo familiar". }\end{array}$ \\
\hline
\end{tabular}


Matriz 4

Consideraciones del docente acerca de la noción de familia que tienen los niños y las niñas extranjeros centroamericanos a su cargo

\begin{tabular}{|c|c|}
\hline Informantes & Respuesta \\
\hline Docente 1 & $\begin{array}{l}\text { "Es lo mismo, la diferencia es que las mujeres cambian de pareja a } \\
\text { menudo y los niños creen que estos compañeros son sus padres, aun- } \\
\text { que no sea así. A veces, las madres les ponen a sus hijos los apellidos } \\
\text { de sus compañeros". }\end{array}$ \\
\hline Docente 2 & $\begin{array}{l}\text { "Los pocos niños nicaragüenses que tengo hacen su familia más ex- } \\
\text { tensiva, ya que conviven en una misma casa, con tíos y abuelos; con- } \\
\text { sideran muy importante a estos miembros como parte de la familia". }\end{array}$ \\
\hline Docente 3 & $\begin{array}{l}\text { "Es similar a los niños costarricenses lo único es que en las familias } \\
\text { nicaragüenses conviven otras personas además del núcleo familia, } \\
\text { por su situación de emigrantes". }\end{array}$ \\
\hline Docente 4 & $\begin{array}{l}\text { "La mayoría siempre extrañan su gente, la familia que tienen aquí es } \\
\text { la que los cuidan y están aquí para "estudiar"." }\end{array}$ \\
\hline Docente 5 & "Es muy parecido a la de los costarricenses". \\
\hline Docente 6 & $\begin{array}{l}\text { "Igual a la respuesta } 2 \text {, ya que mi grupo está constituido por } 33 \text { nica- } \\
\text { ragüenses y un niño tico". }\end{array}$ \\
\hline Docente 7 & $\begin{array}{l}\text { "Los niños extranjeros tienen la noción de que la familia no sola- } \\
\text { mente está integrada por mamá, papá y hermanos, sino que existen } \\
\text { otros miembros, como tíos, abuelos, etc. Además, para ellos es nor- } \\
\text { mal tener familiares en su país de origen, mientras están con su ma- } \\
\text { dre o padre en otro país". }\end{array}$ \\
\hline Docente 8 & $\begin{array}{l}\text { "La familia la constituyen los cohabitantes de su hogar abuelos, pa- } \\
\text { dres, hermanos y tíos y sobrinos, dependiendo de la extensión de las } \\
\text { mismas". }\end{array}$ \\
\hline Docente 9 & "Por supuesto su experiencia propia, su propia familia". \\
\hline
\end{tabular}


incluyen a tíos, abuelos, sobrinos. Una de ellas agrega que, en muchos casos, existe ausencia del padre dentro de estas familias.

Por su parte, tres docentes expresan que la noción de familia es similar entre niños costarricenses y extranjeros centroamericanos. La diferencia radica, según ellas, en que estos últimos incluyen como parte de su familia a otras personas con las que no tienen vínculos sanguíneos, ya sean "padrastros" o personas que debido a su situación de inmigrantes habitan en sus hogares, en un tipo de estructura familiar llamada compleja.

Otros aspectos mencionados por las docentes se relacionan con factores socioeconómicos que crean desintegración en la familia de los niños extranjeros centroamericanos, pues las personas que consideran como familia no se encuentran "bajo un mismo techo", sino que son familia tanto quien los cuida diariamente como aquellos familiares que se encuentran lejos, en su país de origen y a quienes extrañan. Otra docente opina que menciona las personas con quienes vive y convive diariamente el niño, son a las que él integra en su noción de familia.

De lo anterior se podría afirmar que al igual que los niños costarricenses, los niños extranjeros centroamericanos poseen una noción de familia correspondiente a las experiencias y vivencias de su propia realidad. Sin embargo, por razones culturales y económicas en la mayoría de los casos, sus familias están constituidas por diversos miembros (tíos, abuelos, otras personas procedentes de su país de origen), por lo que su noción de familia se basa predominantemente en las estructuras de familias extensas o complejas. Estas mismas razones crean condiciones para que los niños reconozcan como parte de sus familias a otras personas que, aunque actualmente no vivan con ellos, en sus primeros años de vida convivieron y fueron parte de sus experiencias de vida.

Con respecto a la matriz 5, se visualiza como de las 10 maestras que contestaron el cuestionario, 8 dan respuesta a ideas relacionadas especialmente con el ambiente familiar, es decir, la relación existente entre padres e hijos, los cuidados que los niños reciben y las vivencias y dinámicas familiares. Asimismo, 4 docentes consideran que por la situación social del país los factores socioculturales también son aspectos influyentes. Además, 3 de las maestras toman en cuenta los aspectos económicos y 1 opina que la relación con pares es un factor que puede llegar a influir en la noción de familia que los niños elaboran.

Cabe recalcar que por su papel trascendental, se considera a la familia como la primera institución capaz de influir en la noción de familia que desarrollan los individuos, pues es en ésta donde el niño vivencia sus primeras interacciones con personas significativas, lo que le da la posibilidad de tener una participación activa en experiencias diarias que, en última instancia, van a 
Matriz 5

Opinión de las docentes acerca de la elaboración de la noción de familia de sus alumnos preescolares

\begin{tabular}{|c|c|}
\hline Informantes & Respuesta \\
\hline Docente 1 & $\begin{array}{l}\text { “- La relación de ellos con sus padres y hermanos } \\
\text { - La relación que tengan con otros parientes muy cercanos } \\
\text { - El trato que reciben } \\
\text { - El tiempo que pasan los padres con sus hijos”. }\end{array}$ \\
\hline Docente 2 & "Factores culturales". \\
\hline Docente 3 & $\begin{array}{l}\text { "La cultura o el medio de donde vienen. La situación socioeconómi- } \\
\text { ca: al ser de tipo marginada ésta permite el que los niños presenten } \\
\text { diversos problemas de tipo social, agresión, violencia". }\end{array}$ \\
\hline Docente 4 & $\begin{array}{l}\text { “- Situación social } \\
\text { - Patrones de crianza } \\
\text { - Aspectos económicos } \\
\text { - Valores morales y religiosos”. }\end{array}$ \\
\hline Docente 5 & $\begin{array}{l}\text { "Factores son el ambiente, la sociedad de este lugar, los cuidados } \\
\text { que les dan". }\end{array}$ \\
\hline Docente 6 & "Sus vivencias, la televisión, las enseñanzas en las aulas". \\
\hline Docente 7 & "La vivencia, su experiencia personal". \\
\hline Docente 8 & $\begin{array}{l}\text { "Los factores que influyen en la noción de la familia de los niños son } \\
\text { las personas que conviven con ellos en la casa y los comentarios que } \\
\text { ellos escuchan de otros niños". }\end{array}$ \\
\hline Docente 9 & "Por supuesto su experiencia propia, su propia familia". \\
\hline Docente 10 & $\begin{array}{l}\text { “- La emigración de ellos como familia (papá, mamá, hijos) perdien- } \\
\text { do el vínculo con ambos padres } \\
\text { - La inestabilidad de la figura matema-patema } \\
\text { - Inestabilidad económica que los obliga a cambiar de ambiente”. }\end{array}$ \\
\hline
\end{tabular}


influir en su desarrollo integral y, en este caso particularmente, en la concepción de familia que vayan a tener.

Ackerman (citado por Carvajal y Guang, 2003) afirma que la familia modela los tipos de personas que ella misma necesita para llevar a cabo sus funciones. Es por ello que se considera que es en la familia donde el sujeto aprende roles y conductas aceptables según las costumbres y dinámica de su propio núcleo familiar.

\section{CONSIDERACIONES FINALES}

Destaca el hecho de que las docentes consideran que desarrollar en sus aulas la temática de la familia y el conocimiento de las nociones de sus alumnos y alumnas, puede acercarlas a una mayor comprensión del contexto familiar y de las personas significativas que participan e intervienen en el desarrollo de los niños.

$\mathrm{Al}$ indagar con las docentes cómo elaboran los niños preescolares su noción de familia, coinciden en destacar el papel del contexto social, comunal, en el que el niño crece y, específicamente, el ambiente familiar en el que se desarrolla, así como los medios que propician las vivencias, experiencias e interacción con las personas significativas, los criterios de las docentes se orientan especialmente al factor sociocultural y al proceso de internalización por parte de niños y niñas preescolares.

En cuanto al modelo de familia que prevalece en las nociones de sus estudiantes costarricenses, las docentes destacan el modelo tradicional de familia nuclear, que históricamente ha dominado a esta institución social, bajo patrones patriarcales que tienen un fuerte arraigo en la sociedad costarricense.

En cuanto a la noción de familia de los niños extranjeros centroamericanos, las docentes mencionan que en este caso, los niños a su cargo identifican a sus familias dentro de una estructura familiar extensa, porque además de sus padres, incluyen a tíos, abuelos, sobrinos. Señalan que en muchos casos, existe ausencia del padre dentro de estas familias.

Se nota aquí una diferencia entre la noción de familia de niños y niñas costarricenses y extranjeros centroamericanos, desde la visión de las docentes, siendo familia nuclear para los primeros y extensa para los segundos.

Desde la perspectiva docente, al igual que los niños costarricenses, los niños extranjeros centroamericanos poseen una noción de familia muy ligada a las experiencias y vivencias de su propia realidad. No obstante, por razones culturales y económicas en la mayoría de los casos, sus familias están constituidas por diversos miembros (tíos, abuelos, otras personas procedentes de su país 
de origen). En consecuencia, su noción de familia se basa predominantemente en las estructuras de familias extensas o complejas. Estas mismas razones crean condiciones para que los niños reconozcan como parte de su familia a otras personas que, aunque en la actualidad, no vivan con ellos, en sus primeros años sí convivieron y fueron parte de sus experiencias de vida. 


\section{REFERENCIAS}

Alvarado, V. y Rodríguez, L. (2000). Influencia de la nacionalidad de los niños en la relación maestro-niño de alumnos que asisten a un Jardín Infantil Público. Tesis de Licenciatura no publicada, Universidad Nacional, Heredia.

Arce, D., Carballo, A., Castro, K. y Pereira, Z. (2004). La noción de familia que tienen niños costarricenses y extranjeros centroamericanos que asisten a un Jardín Infantil Público. Tesis de Licenciatura no publicada. Universidad Nacional, Heredia, Costa Rica.

Arce, K. (2003). Estudio de necesidades educativas de los inmigrantes nicaragüenses y una propuesta de modelo curricular en la Escuela Santa Isabel, del circuito 01 Venecia de la Regional de San Carlos. Tesis de Licenciatura no publicada. Universidad Estatal a Distancia, San José, Costa Rica.

Arias, G. (2001). Últimos aportes de la investigación en el conocimiento de los menores y sus familias. Cuba: Universidad de La Habana, Facultada de Psicología.

Arnaiz, P. (1999). El reto de educar en una sociedad multicultural y desigual. En línea. Disponible en: www.paidos.redins.es/needirectorio/meiu4htm

Azofeifa, F.; Céspedes, E.; Monge, M. y Vidal M. (2001). Diversidad e Integración Cultural. Heredia: Organización Intemacional para los Migrantes, Ministerio de Educación Pública y Universidad Nacional.

Brenes, G. (1999). Estimulación del volumen y características sociodemográficas de los inmigrantes nicaragüenses en Costa Rica. Tesis de Licenciatura no publicada, Universidad de Costa Rica, San José.

Campos, C. y Smith, M. (1991). Técnicas de diagnóstico familiar y comunal. San José, Costa Rica: Editorial Universidad Estatal a Distancia.

Carballo, M. y Vargas, G. (2002). Nociones que poseen los niños de 4 a 5 años y los conceptos de los maestros sobre el maltrato dentro del aula preescolar. Seminario de Licenciatura no publicado, Universidad Nacional, Heredia.

Carvajal, R. Y Guang, E. (2003). Compendio de lecturas del curso Psicología de la Familia. Heredia: Universidad Nacional.

Contreras, S.; Morelli, G.; Uccelli, L. y Peusner, P. (2002). Actualizaciones en tomo al concepto de "juego" en la clínica psicoanalítica lacaniana con niños. (En Línea). Disponible en: http://www.apertura-psi.org/docs/funcl.doc-

Criado, M. (noviembre-diciembre, 1994). "La educación familiar y su influencia en el desarrollo". Infancia. Madrid. pp. 31-34.

Delgado, I. y Espinoza, S. (1992). Concepto de muerte en niños y niñas preescolares de 5 y 6 años. Tesis de Licenciatura no publicada, Universidad Nacional, Heredia.

Ebanks, E. (1993). Determinantes socioeconómicos de la migración interna. Chile: Centro Latinoamericano de Estadística.

Latinoamericana de Ciencias Sociales. (1999). Amnistía migratoria en Costa Rica. Costa Rica: Facultad Latinoamericana de Ciencias Sociales. 
Fuentes, D. y Ruiz, M. (1988). Adquisición del Concepto de Número en Función del Área Geográfica Urbana Rural en una Muestra de Niños del Estado Mérida. (En Línea). Disponible en: http://www.cindisi.human.ula.ve/f.htm-11K-

Gimeno, J. (1994). Conferencia: Currículo y Democracia. Universidad de Valencia, España.

Gimeno, J. (2001). La educación obligatoria: su sentido educativo y social. Madrid: Ediciones Morata.

Gutiérrez, D. (1999). El niño de preescolar y el pensamiento lógico-matemático: ¿Cómo son sus procesos de apropiación? (En Línea). Disponible en http:// www.colciencias.co/ninos/ondasant.html-21k-

León, A., Pereira, Z. y Castro, M. (2003). Análisis de los procesos cognitivos y pedagógicos que se aplican en el aprendizaje de cinco conceptos básicos del programa de educación preescolar del Ministerio de Educación Pública y el desarrollo de estos mismos conceptos en $2^{\circ}$ y $4^{\circ}$ nivel de la educación general básica. Informe final de Investigación: Universidad Nacional, Heredia, Costa Rica.

Maldjian, B. y Noguera, M. (2000). Proceso de formación de conceptos en niños sordos. Categorías científicas e intuitivas. En línea. Disponible en: http:// www.ub.edu.ar/investigaciones/dt_nuevos/76_maldjian.htm

Marino, Y. (1995). El concepto de ser vivo en niños y niñas preescolares de 5 y 6 años. Tesis de Licenciatura no publicada, Universidad Nacional, Heredia.

Mora, L. (2001). Criterios expresados por el niño para la aceptación o rechazo de coetáneos de 4 a 5 años en el Jardín de Niños Santa María del Circuito 05. Tesis de Licenciatura no publicada, Universidad Nacional, Heredia.

Muriá, I. (2000). La concepción religiosa de la muerte: un estudio evolutivo. (En Línea). Disponible en: http:// www.invsalud.udg.mx/insaluddv3n2/ art345.html-10k-

Polanco, P. y Ramírez, M. (1990). Evolución psicogenética en la construcción de los significados de los conceptos de aves, mueble y fruta en una muestra de niños costarricenses de Kinder y Primer Grado. Tesis de Magister Scientiae en Psicología no publicada, Universidad de Costa Rica, San José.

Ugalde, G. y Vargas, I. (2002). Los preconceptos acerca de género que manifiestan los niños y niñas 4 a 5 años de edad que asisten al interactivo II del ciclo materno infantil de la Escuela Darío Flores Hernández y Once de Abril. Tesis de Licenciatura no publicada, Universidad Nacional, Heredia.

Valerio, S. (1995). El concepto de maestro(a) en preescolares de 5 y 6 años. Tesis de Licenciatura no publicada, Universidad Nacional, Heredia.

Vilas, M. (2001). Congreso: Construir la escuela desde la diversidad y para la igualdad. (En línea). Disponible en: www.nodo50.org/igualdadydiversidad/ g.div_cu.htm.

Villalobos, C. (1998). Concepto de Dios en Niños Preescolares de 5 y 6 años. Tesis de Licenciatura no publicada, Universidad Nacional, Heredia. 


\section{GLOSARIO}

Noción: Son ideas o esquemas representativos que el niño emplea y que se basa en imágenes de un grupo determinado de objetos (Piaget, citado por Marchesi, 1992).

Extranjero Centroamericano: Se entendió como extranjero/a centroamericano/a al niño o niña de edad preescolar (5-6 años) procedente de algún país centroamericano y de padres extranjeros centroamericanos, que cursa estudios en un jardín de niños infantil público de Costa Rica.

Familia: Es un conjunto de elementos (personas con lazos consanguíneos y no consanguíneos), que interactúan entre sí (relación afectiva, económica, moral y espiritual), planeada su orientación hacia una o varias metas, teniendo como fin principal la plena realización como persona de cada uno de sus miembros (García, citado por Aguilar, 1997). 